\title{
Cashmere growth control in Liaoning cashmere goat by ovarian carcinoma immunoreactive antigen-like protein 2 and decorin genes
}

\author{
Mei Jin', Jun-yan Zhang ${ }^{1}$, Ming-xing $\mathrm{Chu}^{2}$, Jun Piao ${ }^{1}$, Jing-ai Piao ${ }^{1}$, and Feng-qin Zhao ${ }^{1, *}$
}

* Corresponding Author: Feng-qin Zhao Tel: +86-13236921570, Fax: +86-0412-85827074,

E-mail: eco-env@163.com

${ }^{1}$ Liaoning Provincial Key Laboratory of Biotechnology and Drug Discovery, Department of Life Sciences,

Liaoning Normal University, Dalian, Liaoning 116029, China

${ }^{2}$ Key Laboratory of Farm Animal Genetic Resources and Germplasm Innovation of Ministry of Agriculture, Institute of Animal Sciences, Chinese Academy of Agricultural Sciences, Beijing 10000, China

ORCID

Mei Jin

https://orcid.org/0000-0002-2349-2568 Jun-yan Zhang

https://orcid.org/0000-0003-3810-5361

Ming-xing Chu

https://orcid.org/0000-0002-5164-0310

Jun Piao

https://orcid.org/0000-0002-7122-244X

Jing-ai Piao

https://orcid.org/0000-0003-2452-1225

Feng-qin Zhao

https://orcid.org/0000-0003-1182-6492

Submitted Jul 5, 2017; Revised Oct 19, 2017; Accepted Feb 7, 2018
Objective: The study investigated the biological functions and mechanisms for controlling cashmere growth of Liaoning cashmere goat by ovarian carcinoma immunoreactive antigenlike protein $2(O C I A D 2)$ and decorin $(D C N)$ genes.

Methods: cDNA library of Liaoning cashmere goat was constructed in early stages. OCIAD2 and $D C N$ genes related to cashmere growth were identified by homology analysis comparison. The expression location of OCIAD2 and $D C N$ genes in primary and secondary hair follicles (SF) was performed using in situ hybridization. The expression of OCIAD2 and DCN genes in primary and $\mathrm{SF}$ was performed using real-time polymerase chain reaction (PCR).

Results: In situ hybridization revealed that OCIAD2 and DCN were expressed in the inner root sheath of Liaoning cashmere goat hair follicles. Real-time quantitative PCR showed that these genes were highly expressed in SF during anagen, while these genes were highly expressed in primary hair follicle in catagen phase. Melatonin (MT) inhibited the expression of OCIAD2 and promoted the expression of DCN. Insulin-like growth factors-1 (IGF-1) inhibited the expression of OCIAD2 and DCN, while fibroblast growth factors 5 (FGF5) promoted the expression of these genes. MT and IGF-1 promoted OCIAD2 synergistically, while MT and FGF5 inhibited the genes simultaneously. MT+IGF-1/MT+FGF5 inhibited DCN gene. RNAi technology showed that OCIAD2 expression was promoted, while that of DCN was inhibited. Conclusion: Activation of bone morphogenetic protein (BMP) signaling pathway upregulated OCIAD2 expression and stimulated SF to control cell proliferation. $D C N$ gene affected hair follicle morphogenesis and periodic changes by promoting transforming growth factor- $\beta$ (TGF- $\beta$ ) and BMP signaling pathways. OCIAD2 and DCN genes have opposite effects on TGF- $\beta$ signaling pathway and inhibit each other to affect the hair growth.

Keywords: Liaoning New-breeding Cashmere Goat; OCIAD2; DCN; Cashmere Growth Mechanism

\section{INTRODUCTION}

Seventy percent of cashmere all over the word comes from China, and the quality of cashmere from China is superior to that from other countries. Liaoning cashmere goats fluff is a good quality and is known as "fiber jewel" in the textile industry. Therefore, it is beneficial to investigate the biology characteristics of any genes that may be involved in regulating cashmere growth. In general, the primary hair follicle (PF) helps in the growth of hair, while the secondary hair follicle (SF) helps in the growth of cashmere [1]. Hair cycle consists of three major phases: anagen (August to October), catagen (after December), and telogen (after February) [2].

Ovarian carcinoma immunoreactive antigen-like protein 2 (OCIAD2) is a protein coding gene that was originally immunoscreened from ascites of an ovarian cancer patient. It is an immunoreactive antigen, and transforms into tumor-specific protein when restrained 
[3]. According to a recent study, transforming growth factor- $\beta$ (TGF- $\beta$ ) signaling has been proved to induce the expression of OCIAD2. Androgen receptor (AR) mainly functions as a DNA-binding transcription factor that regulates gene expression from cytoplasm to intranucleus, and is the possible transcription factor of OCIAD2 in TGF- $\beta$ signaling. In general, OCIAD2 transmits signals through TGF $\beta 1$ - TGF $\beta R 1$ - AROCIAD2. TGF- $\beta$ signaling pathway contains many functional cytokines [4]. According to the activation of different ligands of specific downstream pathways, they are divided into two subfamily pathways, TGF- $\beta$ and bone morphogenetic protein (BMP) [5]. BMP signaling pathway restrains hair follicle formation, and therefore, we speculated that the protein expressed by OCIAD2 gene regulates the growth of hair follicles to some extent.

Decorin (DCN) is one of the most common dermatan sulphate proteoglycan (molecular protein polysaccharide) with small leucine rich proteins. Decorin can significantly reduce the scar formation in skin wounds. Decorin binds to TGF- $\beta 1$ and neutralizes some of its activities as a key regulator of wound contraction and hypertrophic scar formation [6]. Therefore, it showed an indirect impact on the morphological and cyclical changes of hair follicle. Currently, there have been several studies that focused on $D C N$ gene expression in mice and humans at home and abroad, but there were no related studies on DCN expression in cashmere goat. Therefore, the study on $D C N$ gene expression of Liaoning Cashmere goat remains of high value.

Some hormones and cytokines, such as melatonin (MT), insulin-like growth factors-1 (IGF-1), and fibroblast growth factors 5 (FGF5) also play an important role in regulating the cashmere quality. MT is a methoxyindole and its concentration has seasonal changes that coincide with the hair growth cycle of cashmere goat [7]. MT generally affects hair growth by IGFs [8], secrete prolactin indirectly [9], and regulates the genes related to hair in the skin tissue [10]. Similarly, FGF5 can adjust hair growth cycle by extending anagen VI phase [11], and delaying catagen phase [12]. Between the extant elephants and mammoths, two single base substitutions were observed in FGF5, neither of which alters the amino acid sequence [13]. IGF-1 is one of the important regulatory factors that assist animal growth and development $[14,15]$. Seok-Yong Ahn found that IGF-1 had a positive effect on the rate of linear hair growth and maintain the anagen phase [16]. In 2005, Nicole Weger and Thomas Schlake's data identified IGF-1 signaling as an important mitogenic and morphogenetic regulator of hair follicle biology [17]. Also found that exogenous IGF-1 promotes hair growth by stimulating cell proliferation and upregulation of TGF- $\beta 1$ in C57BL/ 6 mice in vivo [18]. Thus, MT, IGF- 1 , and FGF5 act as regulators of hair growth by cell proliferation and transformation of hair cycle, but the underlying mechanisms are still unknown.
Noggin gene is detected in the mesenchyme of hair follicle regulating hair growth and cycle [19]. Studies have found that the expression of BMP-4 mRNA in hair follicles was more than that of the noggin gene in the telogen phase of mesenchymal and epithelial cells of hair follicle [20]. Botchkarev study found that noggin gene mutation in mice demonstrated delayed induction of hair follicles, showing that this gene can work together with BMP-4 and induce the growth of hair follicle in embryonic skin organ [21,22]. BMPs belong to the superfamily that includes TGF- $\beta$ s. Skin epithelial cells express distinct Serine/Threonine kinase receptors from both BMP and TGF- $\beta$ pathways [23]. TGF- $\beta$ regulate the formation of hair follicles through extracellular signal regulated kinase and p38 mitogen activated protein kinase signaling pathways [24].

The quantitative expression of OCIAD2 was increased along with the development of malignant tumor, indicating that the genes are more sensitive to cell division. $D C N$ genes indirectly affect the formation and cyclical changes of hair follicles. This study demonstrated the relation between OCIAD2, DCN gene and cashmere growth through the addition of MT using cytokines to explore the detailed gene functions and RNA interference mechanism. This would lay a theoretical foundation to further explore the cashmere production through regulating the underlying growth mechanism of genes and implement this for enhancement of Cashmere production through breeding.

\section{MATERIALS AND METHODS}

\section{Materials}

Six adult buck Liaoning cashmere goats (Capra hircus) were randomly selected from the breeding field of Liaoning cashmere goat in Liaoning Province, China. Side skin was collected to separate the PF and extract RNA in anagen (July to November), catagen (November to March), and telogen (March to July) phases. The study was approved by the Animal Use Committee at Liaoning Normal University. The anagen skin cDNA library of Liaoning cashmere goat was constructed according to the previous study [25].

\section{In situ hybridization}

After cloning and sequencing, realtime-polymerase chain reaction (RT-PCR) products were purified to generate a template for labeling digoxigenin. Labeling was performed using digoxigenin kit as per the manufacturer's instructions. The prepared probes were stored at $-20^{\circ} \mathrm{C}$. Anagen paraffinized skin tissues, tissue sections were obtained through de-waxing, rehydration, proteinase $\mathrm{K}$ digestion, and thendried for in situ hybridization (ISH). Pre-hybridization was performed with $50 \%$ deionized formamide for 1 hour, and then hybridization was performed at $42^{\circ} \mathrm{C}$ for overnight. The hybridized sections were then washed successively in $2 \times \mathrm{SSC}(150 \mathrm{mM} \mathrm{NaCl}, 15$ 
$\mathrm{mM}$ sodium citrate), $1 \times \mathrm{SSC}, 0.25 \times \mathrm{SSC}$ prior to probe detection with anti-digoxigenin antibodies from sheep. Antibodies were combined using nitroblue tetrazolium chloride/5-bromo4-chloro-3-indolyl phosphate color for $16 \mathrm{~h}$ for immunological detection. The slides were sealed under a neutral resin seal sheet. Then the slides were observed under a BA310 microscope and then photographed.

\section{Cell culture}

$\mathrm{PF}$ and $\mathrm{SF}$ were isolated from skin collected from Liaoning cashmere goats in anagen (October) and catagen (December) phases, while the PF and SF in telogen phase cannot be separated for hair follicle degradation. The cells were cultured in Dulbecco's modified eagle medium at $37^{\circ} \mathrm{C}$ and $5 \% \mathrm{CO}_{2}$ with regular observation and replacement of culture medium. Subculturing was performed when the fibroblasts reached about $70 \%$ to $80 \%$ of the bottle and the skin cells were treated with MT, FGF5, and IGF-1. The concentrations of MT used were $1 \mathrm{~g} / \mathrm{L}, 0.2 \mathrm{~g} / \mathrm{L}, 0.02 \mathrm{~g} / \mathrm{L}$; FGF5 were $10^{-4} \mathrm{~g} / \mathrm{L}, 10^{-5} \mathrm{~g} / \mathrm{L}, 10^{-6} \mathrm{~g} / \mathrm{L}$; and IGF were $10^{-4} \mathrm{~g} / \mathrm{L}, 10^{-5} \mathrm{~g} / \mathrm{L}, 10^{-6} \mathrm{~g} / \mathrm{L}$ the cells for $24 \mathrm{~h}, 48$ $\mathrm{h}$, and $72 \mathrm{~h}$. The maximum inhibition and promotion concentration of MT, IGF-1, and FGF5 have been selected for simultaneous treatment. Combination group was as follows: A. $0.2 \mathrm{~g} / \mathrm{L} \mathrm{MT}$ and $10^{-4} \mathrm{~g} / \mathrm{L}$ IGF-1 for OCIAD2; B. $0.2 \mathrm{~g} / \mathrm{L} \mathrm{MT}$ and $10^{-4} \mathrm{~g} / \mathrm{L}$ FGF5 for OCIAD2; C. $0.02 \mathrm{~g} / \mathrm{L}$ MT and $10^{-5} \mathrm{~g} / \mathrm{L}$ IGF-1 for DCN; D. $0.02 \mathrm{~g} / \mathrm{L}$ MT and $10^{-4} \mathrm{~g} / \mathrm{L}$ FGF5 for DCN. The concentration of cells in each group was $10^{5} / \mathrm{mL}$.

\section{Lentiviral vector knockdown of noggin}

Liaoning cashmere goats skin cells were vaccinated in 6 well culture plates at $37^{\circ} \mathrm{C}$, and cultured in the incubator that contains $5 \% \mathrm{CO}_{2}$. The blank control group, negative control (NC, multiplicity of infection $=300$ ) group and experimental groups were setup at $48 \mathrm{~h}$ of infection. The expression of green fluorescent protein (GFP) of the cells was observed under inverted fluorescent microscope, and pictures were taken to record. Then the total RNA of virus-infected cells was extracted, and then was reverse transcribed into cDNA. Firstly, the RNA and DEPC. $\mathrm{H}_{2} \mathrm{O}$ were kept in the PCR tube. The second step was to add the buffer, RiboLock Ribonuclease inhibitor (New England Biolabs,Ipswich, MA, USA), dNTP mix, and Reverse Tra Ace. Real-time quantitative PCR (RT-qPCR) was then performed to detect the expressions of OCIAD2 and DCN of skin cells infected with Lenti - EGFP - noggin - miR slow virus.

\section{Quantitative real-time PCR}

Total RNA was obtained from PF and SF in anagen and catagen phases. First chain synthesis was performed using Quantscript RT Kit Quant cDNA retroviruses Kit (TaKaRa Company, Dalian, Liaoning, China) according to the instructions. For synthesis of cDNA, we used SYBR Green method according to the SYBR Premix Ex TaqTM II (TaKaRa Company, China) manual for real time quantitative PCR detection. Primer sequences were presented in Table 1.

\section{Statistical analysis}

Statistical analyses were performed using SPSS 17.0 (SPSS Inc., Chicago, IL, USA). Data was expressed as mean \pm standard deviation. A p value less than 0.05 was considered as statistically significant for all tests.

\section{RESULTS}

\section{Localization of OCIAD2 and DCN genes in Liaoning cashmere goats}

Microscopy results demonstrated positive results of ISH, showing grey-green hybridization signals. ISH showed that OCIAD2 and DCN were highly expressed in the inner root sheath (IRS) of PF and SF. Additionally, a clear signal was observed in the matrix cell, but no signal in the medulla layer (MED), (Figure 1a, 1b). Each experiment had a separate control, where no expression signal was found (Figure 1c).

\section{The expression of OCIAD2 and DCN}

The expression of OCIAD2 and DCN genes was more active in SF than PF in anagen phase (Figure 2a). OCIAD2 gene was about 3.89 times, while $D C N$ gene was about 2.69 times than $\mathrm{PD}$ in anagen phase. In catagen, OCIAD2 and $D C N$ genes were more active in PF, where OCIAD2 gene was about 1.22 times, and $D C N$ gene was about 3.75 times. In the telogen phase, the expression of OCIAD2 gene was 0.08 times higher than that of $\beta$-actin (ACTB in human or Actb in mouse) gene and DCN was about 5.58 times (Figure $2 b$ ).

Gene expression of $O C I A D 2$ and $D C N$ in skin cells treated with MT, IGF-1, FGF5

The expression of OCIAD2 in skin cells treated with MT/IGF-1 was lower than the control group individually. The maximum inhibition group was $0.2 \mathrm{~g} / \mathrm{L} \mathrm{MT}$ and $10^{-4} \mathrm{~g} / \mathrm{L}$ IGF- 1 and the inhibition was gradually reduced with time (Figure $3 a, 3 b$ ). Expression of OCIAD2 treated with FGF5 was remarkably increased and the maximum promotion group was $10^{-4} \mathrm{~g} / \mathrm{L}$

Table 1. Oligonucleotide primers used in the experiments

\begin{tabular}{llc}
\hline Gene name & \multicolumn{1}{c}{ Primer sequences $\left(5^{\prime}-3^{\prime}\right)$} & $\begin{array}{c}\text { Annealing } \\
\text { temperature }\left({ }^{\circ} \mathbf{C}\right)\end{array}$ \\
\hline ACTB- $F$ & CCAAAGCCAACCGTGAGAA & 62 \\
ACTB- $R$ & AGAGGCGTACAGGGACAGCA & \\
$D C N-F$ & GCAATCGGCTCCAACGA & 58 \\
$D C N-R$ & GGACTGGGTTGCTGAAAGG & \\
OCIAD2-F & GCTTGTCACCCAAGGACTGGTCC & 57 \\
OCIAD2- $R$ & CCACGCAGCTGGCCTTCAAAGG & \\
\hline
\end{tabular}

$A C T B, \beta$-actin gene; $D C N$, Decorin; OCIAD2, ovarian carcinoma immunoreactive antigen-like protein 2. 
(a)

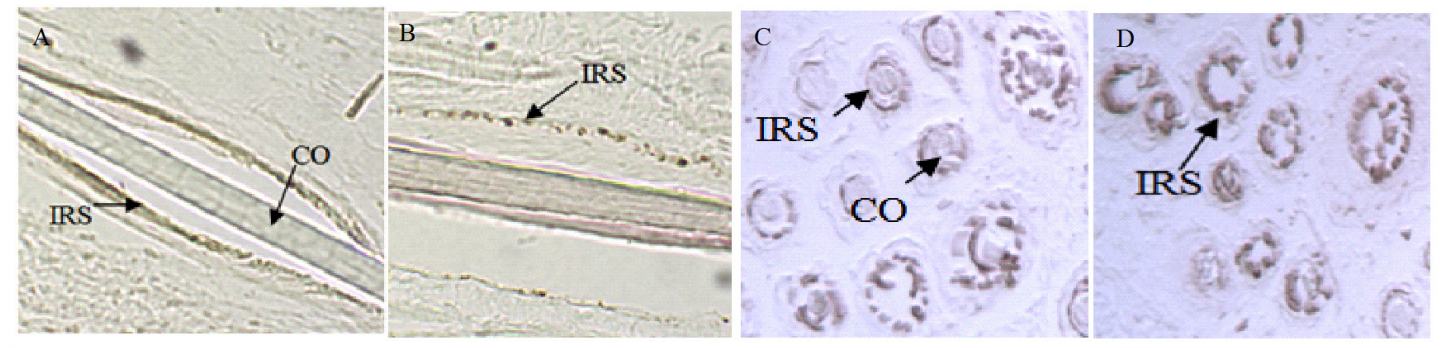

(b)
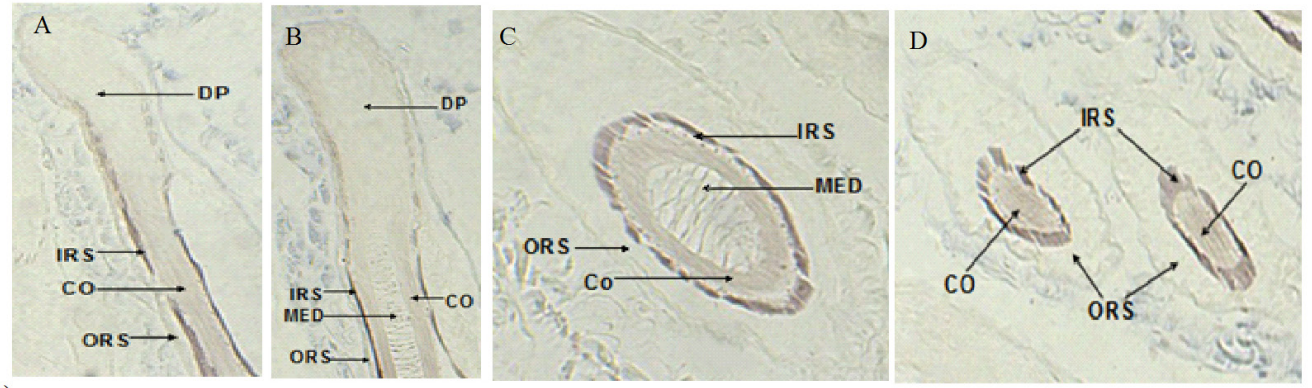

(c)
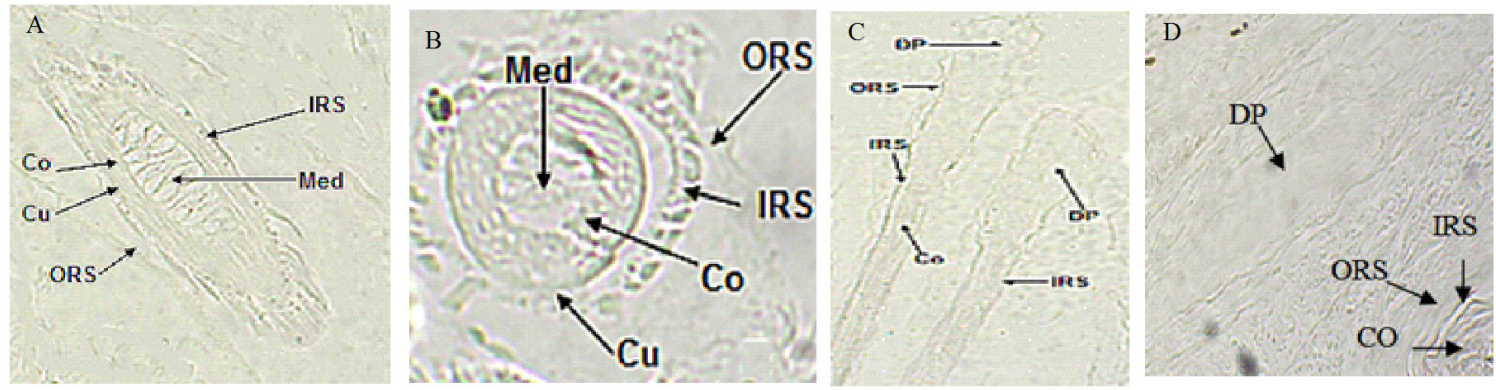

Figure 1. The expression of OCIAD2 and DCN genes in the cashmere goat PF and SF. (a) The expression of OCIAD2 gene in the cashmere goat PF and SF, (A) The expression of OCIAD2 gene in the PF (slitting section, 100x): (B) the expression of OCIAD2 gene in the SF (slitting section, 100x): (C, D) the expression of OCIAD2 gene in the PF and SF (transverse line, 100x). (b) The expression of DCN gene in the cashmere goat PF and SF (A) the expression of OCIAD2 gene in the PF (slitting section, 100x); (B) the expression of OCIAD2 gene in the SF (slitting section, 100x); (C) the expression of OCIAD2 gene in the PF (transverse line, 100x); (D) the expression of $D C N$ gene in SF (transverse line,100x). (c) A, B, C, D as control (100x). OCIAD2, ovarian carcinoma immunoreactive antigen-like protein 2; DCN, decorin; PF, primary hair follicle; SF, secondary hair follicle.

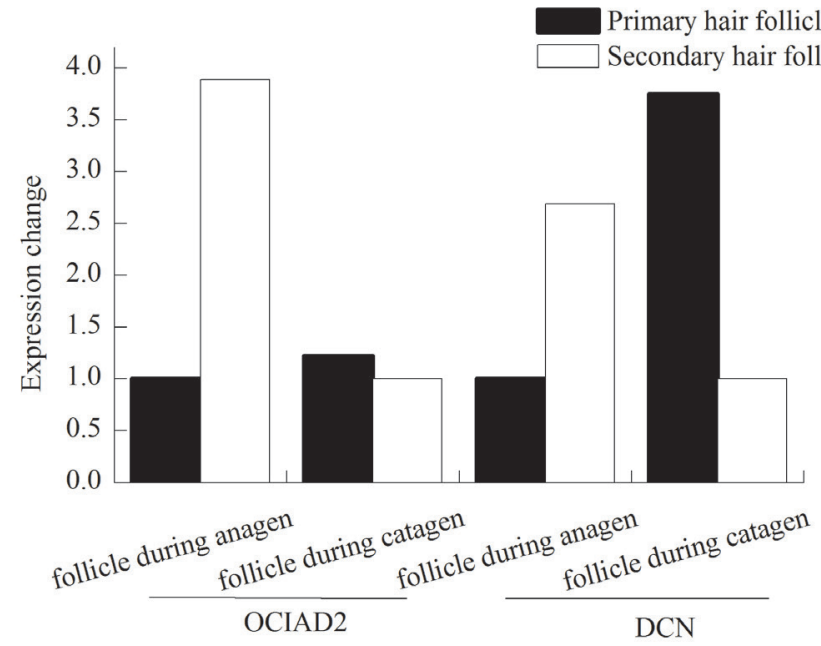

(a)

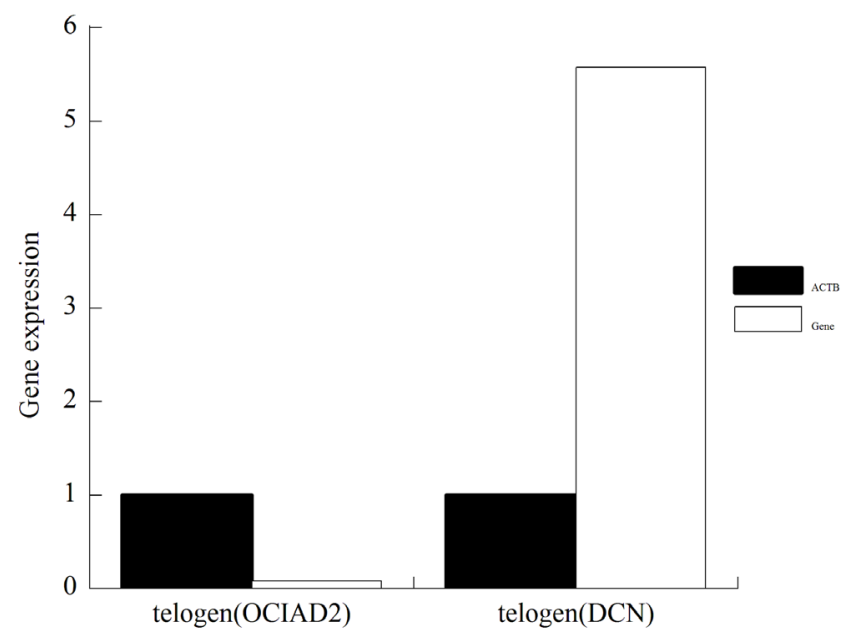

(b)

Figure 2. (a) Expression of OCIAD2, DCN in anagen, catagen. (b) Expression of OCIAD2, DCN in telogen. OCIAD2, ovarian carcinoma immunoreactive antigen-like protein 2; DCN, decorin. ${ }^{*} p<0.05,{ }^{* *} p<0.01$. 
for $24 \mathrm{~h}$ (Figure 3c).

$D C N$ gene expression was promoted by $0.02 \mathrm{~g} / \mathrm{L}$ of MT and was most significant after $48 \mathrm{~h}$ (Figure 3a). The expression of DCN in skin cells treated with FGF5 was higher than the control group and maximum promotion group $\left(10^{-4} \mathrm{~g} / \mathrm{L}\right)$ (Figure 3c). Expression of DCN treated with IGF-1 was significantly inhibited and with time, and inhibitory effect showed a reduction (Figure 3b).

We choose the period during which gene changes were most significant when treated individually with MT, IGF-1, and FGF5 to do synergy test. After treatment with MT and IGF-1 simultaneously, the expression of OCIAD2 was increased and found to be the most significant. After treatment with MT and FGF5 simultaneously, the expression of OCIAD2 was inhibited and most significant at 24 hours. The expres- sion of $D C N$ gene was inhibited after treatment with MT and IGF-1. The expression of $D C N$ gene was promoted after treatment with MT and FGF5 (Figure 3d).

The expression of OCIAD2 and DCN in skin cells after knockdown of noggin

Figure 4 showed the pictures of before and after infection and Figure 5 showed the results of qPCR. Compared with blank group, preliminary experimental results showed the best genes for extracting RNA primers at annealing temperature and amount of template after noggin gene interference. Then the RNA of blank, NC and noggin gene interference group were extracted. RNA was reverse transcribed into cDNA by qPCR, which in turn analyzes $A C T B, O C I A D 2, D C N$ gene expressions and showed better amplification and melting curves.

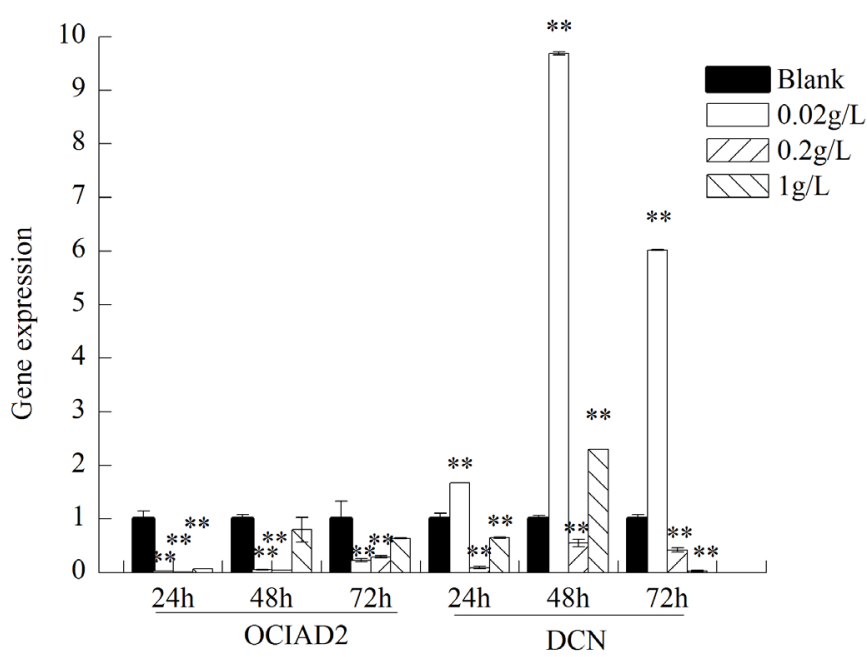

(a)

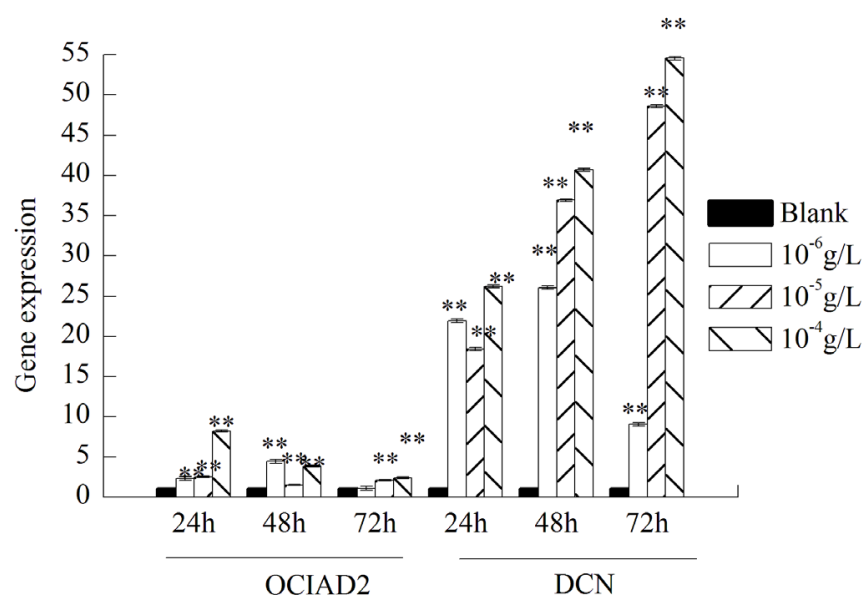

(c)

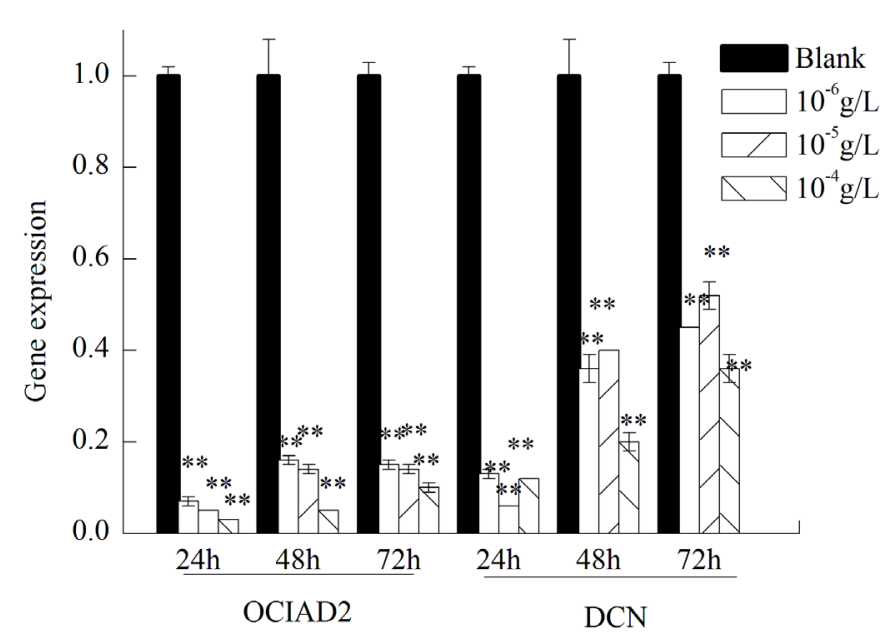

(b)

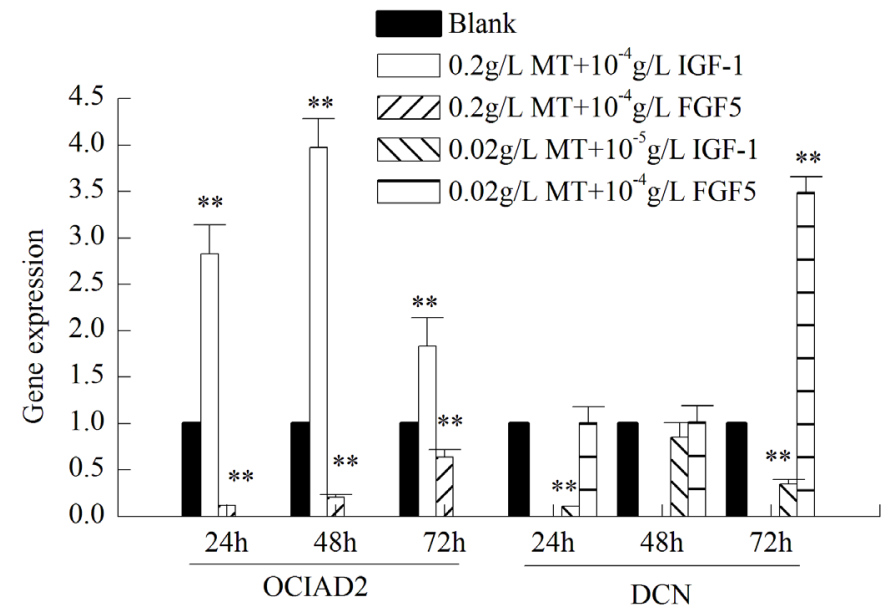

(d)

Figure 3. MT, IGF-1, FGF5 deal with dermal fibroblasts of cashmere goat. (a) Reagent is MT, expression of OCIAD2 and DCN as a function of MT treatment for 24, 48, or 72 hour. (b) Expression of OCIAD2 and DCN as a function of IGF-1 treatment for 24, 48, or 72 hour. (c) Expression of OCIAD2 and DCN as a function of FGF5 treatment for 24,48 , or 72 hour. (d) Expression of OCIAD2 and DCN during simultaneous treatment with MT and FGF5 or IGF-1. A1, $0.02 \mathrm{~g} / \mathrm{L} \mathrm{MT}$ and $10^{-4} \mathrm{~g} / \mathrm{L}$ FGF5 for $24 \mathrm{~h} ; \mathrm{A2}, 0.2 \mathrm{~g} / \mathrm{L}$ MT and $10^{-4} \mathrm{~g} / \mathrm{L} \mathrm{FGF5}$ for $24 \mathrm{~h} ; \mathrm{A} 3,0.02 \mathrm{~g} / \mathrm{L} \mathrm{MT}$ and $10^{-6} \mathrm{~g} / \mathrm{L} \mathrm{FGF5} \mathrm{for} 24 \mathrm{~h} ; \mathrm{A} 4,0.2 \mathrm{~g} / \mathrm{L} \mathrm{MT}$ and $10^{-6} \mathrm{~g} / \mathrm{L} \mathrm{FGF5}$ for $24 \mathrm{~h} ;$ and B, $0.02 \mathrm{~g} / \mathrm{L} \mathrm{MT}$ for $24 \mathrm{~h}$ and $10^{-4} \mathrm{~g} / \mathrm{L}$ IGF-1 for 24 h. MT, melatonin; IGF-1, insulin-like growth factors-1; FGF5, fibroblast growth factors 5; OCIAD2, ovarian carcinoma immunoreactive antigen-like protein 2; DCN, decorin. 
(a)

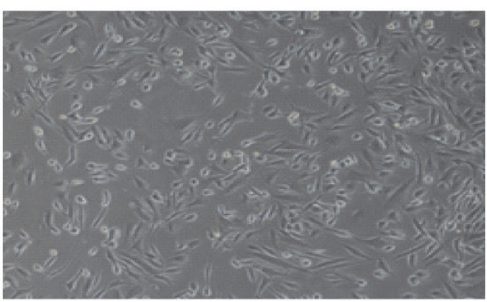

(b)

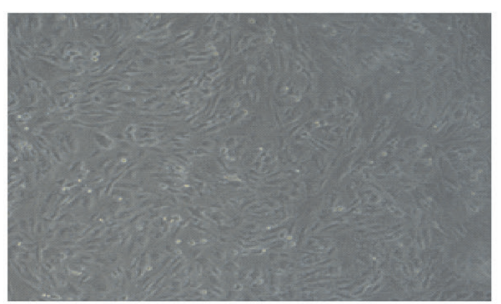

(d)

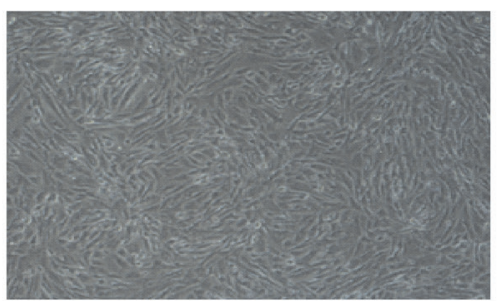

(f)

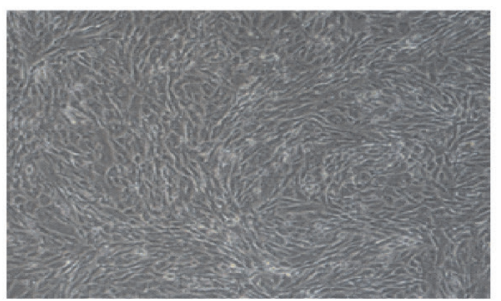

(c)

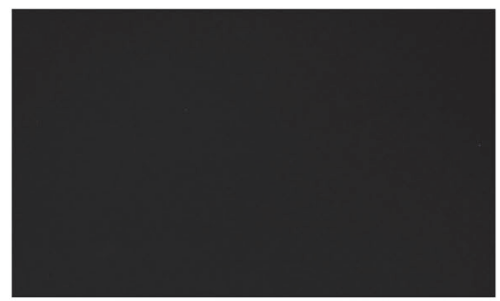

(e)

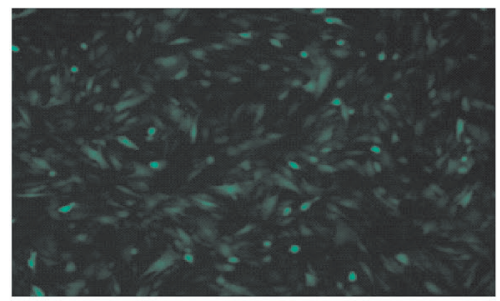

(g)

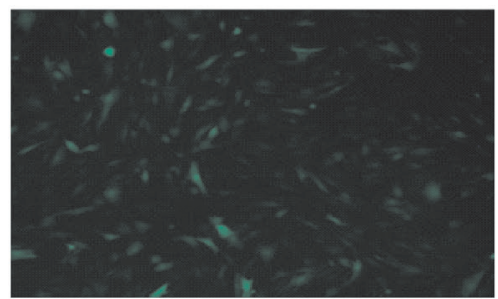

Figure 4. Cashmere goats skin cells before viral infection. (a) (10x) and cashmere goats skin cells after $48 \mathrm{~h}$ virus infection. (b), (c) are lentivirus uninfected cell control groups (10x). (d), (e) are negative control (NC) control groups of cashmere goat skin (10x). (f), (g) are pLenti6.3-EGFP-noggin-miR3 control groups (10x). (a), (b), (d), (f) bright visual fields; (c), (e), (g), dark visual fields.

After NC virus infection, OCIAD2 gene expression was increased by about 1.15 times that of the blank group. After noggin lentivirus infection, OCIAD2 gene expression was about 3.19 times that of the NC virus. After NC virus infection, the expression of $D C N$ gene was about 1.10 times than that of the blank group. After noggin lentivirus infection, $D C N$ gene expression was about 0.88 times that of the NC virus, which was distinct (Figure 5).

\section{DISCUSSION}

In situ hybridization demonstrated the expression of OCIAD2 and $D C N$ genes in both IRS and matrix cells. IRS of the hair shaft is surrounded by a rigid structure of small leather sheath, Huxley layer and Henle layers, determining the shape of hair shaft. The interaction between matrix cell and dermal papilla is crucial for the growth of hair follicle [26]. ISH results confirmed that the two genes were involved in the regulation of hair follicle development.

Studies showed that the SF was involved in the growth of cashmere, while PF in the growth of wool. So, the higher the ratio of $\mathrm{SF} / \mathrm{PF}$ is, the more wool is produced. As measured by 


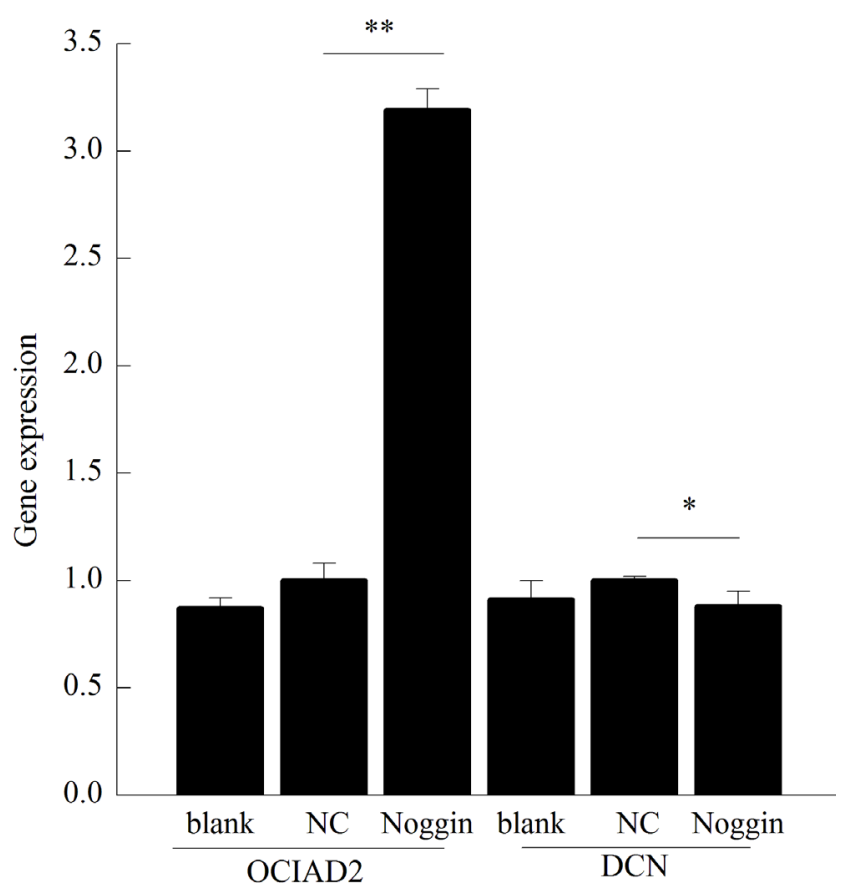

Figure 5. Expressions of OCIAD2 and DCN in cells infected with lentiviral RNAi expression vector targeting. NC, noggin. OCIAD2, ovarian carcinoma immunoreactive antigen-like protein 2; DCN, decorin.

real-time PCR in anagen phase, OCIAD2 and DCN SF/PF values were significantly higher than that in catagen phase. In telogen phase, when there is no growth of cashmere observed, the expression of OCIAD2 gene was lower compared to $D C N$ gene, proving that the gene expression was different during different stages of hair follicle growth. Therefore, OCIAD2 and $D C N$ genes were involved in the regulation of cashmere production process of SF, demonstrating a close relationship with the cyclical changes.

The expression of OCIAD2 in fibroblasts was inhibited after treatment with MT/IGF-1, but MT+IGF-1 promoted OCIAD2 gene expression. The MT and FGF5 can change the regulatory effect of OCIAD2. MT stimulates SF to increase the production of cashmere, which in turn promote the growth of wool fiber, and IGF1 controls cell proliferation. Their negative correlation indicates protein degradation of OCIAD2 and stimulates SF cell proliferation. FGF5 has positive effects on OCIAD2 gene. MT+FGF5 inhibit OCIAD2 gene expression and showed that MT can weaken FGF5' regulatory effect on OCIAD2 gene.

MT may also control hair follicle growth cycle of mice by regulating the expression of MT2 and orphan nuclear receptor $\alpha(\mathrm{ROR} \alpha)$ [27]. FGF signaling can inhibit BMP signaling, maintain multipotency of hair follicle stem cells and promote the long-term hair follicle stem cell proliferation ability [28]. It was speculated that the $D C N$ gene inhibits BMP signaling to regulate hair follicle transition to the telogen and induce catagen phase by adjusting the RORa and MT2. IGF-1 re- strains $D C N$ gene. MT and IGF-1 work together to inhibit DCN, showing that IGF-1 plays a leading role when MT and IGF-1 act together.

Noggin activates BMP signaling pathways, and inhibits the expression of $D C N$ gene, promotes OCIAD2 gene. Therefore, $D C N$ and OCIAD2 genes inhibit reciprocally and regulate cashmere growth through BMP signaling pathway. OCIAD2 was activated by integration between TGF- $\beta$ and its receptor. $D C N$ gene is regarded as a negative factor of TGF- $\beta$. After inhibition of $D C N$ gene, TGF- $\beta$ was activated and integrated with its receptor to activate OCIAD2 gene. Foitzik et al [29] proved that TGF- $\beta 1$ knock out significantly delayed the transition from anagen to catagen phase of mice. Therefore, TGF- $\beta 1$ induces the transition of hair follicles from anagen to catagen phase by inhibiting cell proliferation and promoting cell apoptosis.

\section{CONCLUSION}

Our study identified two genes in PF and SF and regulate different expression stages of PF and SF. Besides, the expression of OCIAD2 and DCN genes were regulated by adding MT, FGF5, and IGF-1 exogenously or by interfering with noggin expression. It has been found that after integration of TGF- $\beta$ and its receptor, OCIAD2 gene activates BMP signaling pathway to control SF cell proliferation. FGF5 promotes DCN gene, suppresses BMP signals, and promotes the transformation of hair follicles in the telogen phase. The two genes inhibit reciprocally to adjust the growth of cashmere. These results encourage the research on OCIAD2 and DCN genes, and lay a foundation for studying the relation between skin and hair follicles of Liaoning cashmere goat.

\section{CONFLICT OF INTEREST}

We certify that there is no conflict of interest with any financial organization regarding the material discussed in the manuscript.

\section{ACKNOWLEDGMENTS}

This work was supported by the National Natural Science Foundation of China (grant number 31772557); and the Natural Science Foundation of Liaoning Province (grant number 2017 0540577); and the Scientific Research Projects in Liaoning Province Department of Education (grant number L201683625; L2015290).

\section{REFERENCES}

1. Lavker RM, Sun TT, Oshima H, et al. Hair follicle stem cells. J Investig Dermatol Symp Proc 2003;8:28-38. 
2. Stenn KS, Paus R. Controls of hair follicle cycling. Physiol Rev 2001;81:449-94.

3. Luo LY, Soosaipillai A, Diamandis EP. Molecular cloning of a novel human gene on chromosome $4 \mathrm{p} 11$ by immunoscreening of an ovarian carcinoma cDNA library. Biochem Biophys Res Commun 2001;280:401-6.

4. Zhang R, Zhao C, Xiong Z, Zhou X. Pathway bridge based multiobjective optimization approach for lurking pathway prediction. Biomed Res Int 2014;2014:Article ID 351095.

5. Guo X, Wang XF. Signaling cross-talk between TGF-beta/BMP and other pathways. Cell Res 2009;19:71-88.

6. Zhang Z, Li XJ, Liu Y, et al. Recombinant human decorin inhibits cell proliferation and downregulates TGF-betal production in hypertrophic scar fibroblasts. Burns 2007;33:634-41.

7. Duan C, Xu J, Sun C, Jia Z, Zhang W. Effects of melatonin implantation on cashmere yield, fibre characteristics, duration of cashmere growth as well as growth and reproductive performance of Inner Mongolian cashmere goats. J Anim Sci Biotechnol 2015;6:22.

8. Dicks P, Morgan CJ, Morgan PJ, Kelly D, Williams LM. The localisation and characterisation of insulin-like growth factor-I receptors and the investigation of melatonin receptors on the hair follicles of seasonal and non-seasonal fibre-producing goats. J Endocrinol 1996;151:55-63.

9. Nixon AJ, Choy VJ, Parry AL, Pearson AJ. Fiber growth initiation in hair follicles of goats treated with melatonin. J Exp Zool 1993;267:47-56.

10.Fu S, Zhao H, Zheng Z, Li J, Zhang W. Melatonin regulating the expression of miRNAs involved in hair follicle cycle of cashmere goats skin. Yi Chuan 2014;36:1235-42.

11. Hebert JM, Rosenquist T, Gotz J, Martin GR. FGF5 as a regulator of the hair growth cycle: evidence from targeted and spontaneous mutations. Cell 1994;78:1017-25.

12. Sundberg JP, Rourk MH, Boggess D, et al. Angora mouse mutation: altered hair cycle, follicular dystrophy, phenotypic maintenance of skin grafts, and changes in keratin expression. Vet Pathol 1997;34:171-9.

13. Roca AL, Ishida Y, Nikolaidis N, et al. Genetic variation at hair length candidate genes in elephants and the extinct woolly mammoth. BMC Evol Biol 2009;9:232.

14. Philpott MP, Sanders DA, Kealey T. Effects of insulin and insulin-like growth factors on cultured human hair follicles: IGF-I at physiologic concentrations is an important regulator of hair follicle growth in vitro. J Invest Dermatol 1994;102:85761.

15. Bhora FY, Dunkin BJ, Batzri S, et al. Effect of growth factors on cell proliferation and epithelialization in human skin. J Surg
Res 1995;59:236-44.

16. Ahn SY, Pi LQ, Hwang ST, Lee WS. Effect of IGF-I on Hair Growth Is Related to the Anti-Apoptotic Effect of IGF-I and Up-Regulation of PDGF-A and PDGF-B. Ann Dermatol 2012; 24:26-31.

17. Weger N, Schlake T. IGF-I signalling controls the hair growth cycle and the differentiation of hair shafts. J Invest Dermatol 2005;125:873-82.

18. Li J, Yang Z, Li Z, et al. Exogenous IGF-1 promotes hair growth by stimulating cell proliferation and down regulating TGFbetal in C57BL/6 mice in vivo. Growth Horm IGF Res 2014; 24:89-94.

19.Sun Y, Nakanishi M, Sato F, et al. Trps1 deficiency inhibits the morphogenesis of secondary hair follicles via decreased Noggin expression. Biochem Biophys Res Commun 2015;456:721-6.

20.Pregizer SK, Mortlock DP. Dynamics and cellular localization of Bmp2, Bmp4, and Noggin transcription in the postnatal mouse skeleton. J Bone Miner Res 2015;30:64-70.

21. Botchkarev VA, Botchkareva NV, Roth W, et al. Noggin is a mesenchymally derived stimulator of hair-follicle induction. Nat Cell Biol 1999;1:158-64.

22. Botchkarev VA, Botchkareva NV, Nakamura M, et al. Noggin is required for induction of the hair follicle growth phase in postnatal skin. FASEB J 2001;15:2205-14.

23. Oshimori N, Fuchs E. Paracrine TGF-beta signaling counterbalances BMP-mediated repression in hair follicle stem cell activation. Cell Stem Cell 2012;10:63-75.

24. Picinato MC, Hirata AE, Cipolla-Neto J, et al. Activation of insulin and IGF-1 signaling pathways by melatonin through MT1 receptor in isolated rat pancreatic islets. J Pineal Res 2008; 44:88-94.

25. Jin M, Liu N, Yuan S, et al. Construction of a cDNA library and identification of genes from Liaoning cashmere goat. Livest Sci 2014;164:26-34.

26. Schneider MR, Schmidt-Ullrich R, Paus R. The hair follicle as a dynamic miniorgan. Curr Biol 2009;19:R132-42.

27. Winczyk K, Pawlikowski M, Guerrero JM, Karasek M. Possible involvement of the nuclear RZR/ROR-alpha receptor in the antitumor action of melatonin on murine Colon 38 cancer. Tumour Biol 2002;23:298-302.

28. Huang J, Dattilo LK, Rajagopal R, et al. FGF-regulated BMP signaling is required for eyelid closure and to specify conjunctival epithelial cell fate. Development 2009;136:1741-50.

29. Foitzik K, Lindner G, Mueller-Roever S, et al. Control of murine hair follicle regression (catagen) by TGF-betal in vivo. FASEB J 2000;14:752-60. 